\title{
Cytogenetic toxicity and gonadal effects of 17 a-methyltestosterone in Astyanax bimaculatus (Characidae) and Oreochromis niloticus (Cichlidae)
}

C.L.G. Rivero-Wendt, A.L. Miranda-Vilela, M.F.N. Ferreira, A.M. Borges and C.K. Grisolia

Departamento de Genética e Morfologia, Instituto de Ciências Biológicas, Universidade de Brasília, Brasília, DF, Brasil

Corresponding author: C.K. Grisolia

E-mail: grisolia@unb.br

Genet. Mol. Res. 12 (3): 3862-3870 (2013)

Received January 23, 2013

Accepted July 28, 2013

Published September 23, 2013

DOI http://dx.doi.org/10.4238/2013.September.23.4

\begin{abstract}
The synthetic hormone, 17- $\alpha$-methyltestosterone (MT), is used in fish hatcheries to induce male monosex. Androgenic effects on various fish species have been reported; however, few studies have assessed possible genotoxic effects, although there are concerns about such effects in target and non-target species. We evaluated genotoxic and gonadal effects of MT in adult tilapia (Oreochromis niloticus) and Astyanax bimaculatus (a common native non-target fish in Brazil). Fish were fed for 28 days with ration containing MT $(60 \mathrm{mg} / \mathrm{L})$, a normal dose used in fish farming. Evaluation of MT genotoxicity was carried out through micronucleus test, nuclear abnormality, and comet assay analyses on peripheral erythrocyte cells collected by cardiac puncture. There were no significant differences in micronucleus frequencies and DNA damage in both species; however, MT caused cytogenetic toxicity in the non-target species, $A$. bimaculatus, with significantly increased erythrocyte nuclear abnormalities. Histopathological analyses of the female gonads of $O$. niloticus revealed that MT significantly inhibited the development of mature oocytes, while in A. bimaculatus it provoked
\end{abstract}


significant inhibition of spermatozoa production. We concluded that discharge of fish-hatcheries water onto the surface of aquatic ecosystems should be avoided due to risks to reproduction of native species.

Key words: $17-\alpha-$-Methyltestosterone; Endocrine disruptor; Fish micronucleus; Comet assay; Histopathology

\section{INTRODUCTION}

17- $\alpha$-Methyltestosterone (MT) is a synthetic hormone used in fish hatcheries to induce anabolic and androgenic effects (Vick and Hayton, 2001), such as sex reversal in cultivated fish species. The androgenic effects of environmental endocrine disruptor chemicals (EDC) on aquatic organisms have received increasing attention, particularly with respect to fish, since they are the target of these chemicals to induce sex reversal (Papoulias et al., 2000). In fact, in polluted aquatic areas and aquaculture, physiologic and developmental abnormalities have been reported in feral fish, including increased vitellogenin (VTG) concentrations, gonadal intersexuality in male fish (Kang et al., 2008), decreased plasma concentrations of sex steroids, and adversely affected gonadal status (relative weight and histopathology) in both sexes (Ankley et al., 2001). Thus, there is concern about and resistance to the use of hormones in food production, and more efforts need to be made to understand how androgenic chemicals used in aquaculture can adversely affect wildlife, fish reproduction and food production.

The synthetic androgen MT, widely used as a reference chemical to induce male monosex, is considered an endocrine disrupter in fish (Smith, 1974; Pandian and Sheela, 1995; Ankley et al., 2001; Zerulla et al., 2002; Arslan and Phelps, 2004; Hornung et al., 2004; Pawlowski et al., 2004; Kang et al., 2008; Grisolia et al., 2009). However, few studies have been performed to assess the possible genotoxic effect of MT or to examine any aspect of DNA damage caused by testosterone treatment in organs of intact animals. This paucity of studies may be because sex steroids are recognized as non-genotoxic carcinogens. However, controversial results have been reported in this regard (Hana et al., 2008). Since the micronucleus test is a very sensitive and useful method that can detect both clastogenic and aneugenic activity (al-Sabti and Metcalfe, 1995), it is a good tool for monitoring this damage. Moreover, because the comet assay is widely accepted as a standard method for assessing DNA damage in individual cells, it could be also used to evaluate genotoxicity (Dusinska and Collins, 2008; McKenna et al., 2008; Collins, 2009). Although this is not the only way to measure oxidative DNA damage, it is one of the most sensitive and accurate (Collins, 2009). It is a valuable tool for population monitoring, for example, in assessing mechanisms of mutagenesis, genotoxicity and ecological monitoring, and for investigating DNA damage and repair in different cell types in response to a range of DNA-damaging agents, among others (Dusinska and Collins, 2008; McKenna et al., 2008; Collins, 2009). Thus, the micronucleus (MN) test, assessment of nuclear abnormalities (NA) (da Silva and Fontanetti, 2006) and the comet assay are excellent techniques used in vivo to test the genotoxicity of environmental pollutants such as EDC (al-Sabti and Metcalfe, 1995; Grisolia and Starling, 2001; Pacheco and Santos, 2002; Bolognesi et al., 2006; Kim and Hyun, 2006; Rivero et al., 2008).

The MN test in peripheral erythrocytes of fish has been widely employed for both in situ exposure to environmental waters and laboratory treatments in vivo (Ayllon and Garcia-Vazquez, 2000). There are many compounds that induce genotoxic effects with or without directly dam- 
aging DNA. MN can be produced from chromosomal fragments or whole chromosomes that lag behind in cell division due to lack of a centromere, damage of the centromere or defect in cytokinesis (Udroiu, 2006). The comet assay has been used in aquatic genotoxicology with both vertebrate and invertebrate organisms. In vivo data on fish have been obtained with redbreast sunfish (Lepomis auritus), hard head catfish (Anus felis), bullhead (Ameirurus nebulosus) and carp (C. carpio) (Buschini et al., 2004).

In Brazilian fish hatcheries, this hormone is used to induce male monosex in Oreochromis niloticus larvae through feeding with fish chow for 28 days. In our study, adult individuals in the reproductive period of Oreochromis niloticus (target for MT in fish farming) and Astyanax bimaculatus (non-target for MT in fish hatcheries) were fed for 28 days with food containing MT to check the possible genotoxic and reproduction effects on the species studied. The genotoxic effects of MT were evaluated by MN, AN and CA, and the gonadal effects and reproductive maturation were evaluated through morphometric analysis performed by light microscopy, to type $\mathrm{V}$ oocytes and quantify spermatozoa in both species.

\section{MATERIAL AND METHODS}

\section{Chemical test}

$17 \alpha$-Methyltestosterone (MT; 90\% purity) was purchased from Bioativa pharmacy (Paraná, Brazil). In laboratory conditions, fish exposure occurred in a similar way as in fish farms. An MT stock solution (1000 mg/L) was prepared by dissolving MT in absolute alcohol. The working solution was prepared adding $60 \mathrm{~mL}$ of stock solution to $440 \mathrm{~mL}$ of hydrated ethanol $(96 \mathrm{GL})$ per $\mathrm{kg}$ of dry food $(60 \mathrm{mg} / \mathrm{L})$, which allowed the addition of the required dosage in a tank with less than $0.05 \mathrm{~mL}$ alcohol solution (Smith, 1974). Afterwards, food containing MT solution was dried in the dark for 15 days, for the natural evaporation of the alcohol, and it was then stored at $4^{\circ} \mathrm{C}$. The daily amount of feed accounted for $20 \%$ of body weight of the larvae in the first two weeks and $10 \%$ of body weight in the last two weeks.

\section{Study design}

A. bimaculatus and O. niloticus were obtained from fish farms in Brasilia, Brazil and were kept in the laboratory in glass tanks of $200 \mathrm{~L}$ for one week to acclimatize, keeping water temperature at $24 \pm 2^{\circ} \mathrm{C}$ and $\mathrm{pH} 7.0$, and controlling ammonia level with constant aeration. Fish chosen for the tests ( 9 to $14 \mathrm{~cm}$ in length) were in the initial maturation stage (reproductively active), weighing approximately $19 \mathrm{~g}$. The animals were randomly divided into two treatment groups: those that received food with MT and those that received food without MT. The tanks were monitored for 28 days. Afterwards, the animals were euthanized, blood samples were collected to perform the MN test and comet assay, and gonads were surgically removed for histological processing.

All procedures described were reviewed and approved by the institutional Ethics Committee for Animal Research (Institute of Biological Science, University of Brasília), No. 100273/2009.

\section{Analysis of MN and NA}

The MN test was carried out as described by (Hooftman and Raat, 1982) for fish erythro- 
cyte cells. Peripheral blood was drawn by cardiac puncture with a heparinized syringe and smears were immediately prepared with a drop of blood $(50 \mu \mathrm{L})$. Slides were dried at room temperature for $24 \mathrm{~h}$, fixed with methanol for $15 \mathrm{~min}$ and stained with Giemsa. Two smears were performed for each individual. Three thousand erythrocytes were analyzed per fish for the presence or absence of MN and NA, under an oil immersion objective (1000X). The criteria for the identification of fish micronucleated erythrocytes were as follows: (a) MN should be smaller than one-third of the main nuclei, (b) MN must not touch the main nuclei, and (c) MN must not be refractive and should be the same color and intensity as the main nuclei. Groups of 10 O. niloticus and A. bimaculatus comprised the control group and treatment group with MT in a 200-L aerated aquarium for 28 days.

\section{Comet assay}

This assay was performed as described by (Singh et al., 1988), with some modifications for fish as previously reported by Rivero et al. (2008), as described below. The cell suspension placed in the microtube was mixed with $120 \mu \mathrm{L}$ low-melting agarose $\left(37^{\circ} \mathrm{C}\right)$. Next, $500 \mu \mathrm{L}$ erythrocyte-agarose suspension was placed on a fully frosted slide pre-coated with standard agarose $(1.5 \%)$ and covered with a coverslip. The slides were then placed on ice for 15 min to allow complete agarose polymerization and afterwards in a chilled lysing solution (2.5 M NaCl, $100 \mathrm{mM}$ EDTA, $10 \mathrm{mM}$ Tris- $\mathrm{HCl}, 1 \% \mathrm{~N}$-laurolyl-sarcosine, 1\% Triton X-100, $10 \%$ DMSO; $\mathrm{pH} 10)$. Next, the slides were placed on a horizontal gel electrophoresis platform and covered with a chilled alkaline solution consisting of $300 \mathrm{mM} \mathrm{NaOH}$ and $1 \mathrm{mM} \mathrm{Na} \mathrm{FDTA}_{2}$ ( $\mathrm{pH}$ 13), left in the dark at $4^{\circ} \mathrm{C}$ for $30 \mathrm{~min}$, and the DNA was then electrophoresed at $4^{\circ} \mathrm{C}$ in the dark for $30 \mathrm{~min}$ at $25 \mathrm{~V}$ and approximately $350 \mathrm{~mA}$. The slides were gently rinsed twice with $400 \mathrm{mM}$ Tris- $\mathrm{HCl}(\mathrm{pH}$ 7.5) to neutralize the alkali. Each slide was stained with $30 \mu \mathrm{L} 20$ $\mu \mathrm{g} / \mathrm{mL}$ ethidium bromide and covered with a coverslip. One hundred cells from each replicate were randomly chosen (50 from each duplicate slide), and analyzed under a fluorescence microscope (Axioskop-2, Carl Zeiss), with a 510-560 nm filter and a $590 \mathrm{~nm}$ barrier filter, with a magnification of $400 \mathrm{X}$. For damage index calculation, cells were sorted into four classes, according to tail size. The index of damage (ID) is the sum of classes of the 100 cells analyzed per fish, and may vary from 0 (all cells undamaged - 0 x 100) to 400 (all cells highly damaged $-4 \mathrm{x} 100$ ). The damage index is based on the length of migration and on the amount of DNA in the tail, and it is considered a sensitive measurement of detectable DNA damage.

$$
\mathrm{ID}_{\text {(au) }}=\frac{\mathrm{N} 1+2 \mathrm{~N} 2+3 \mathrm{~N} 3+4 \mathrm{~N} 4}{\mathrm{~S} / 100}
$$

where ID = index of DNA damage, au = arbitrary unit, N1 - N4 = nucleoids in levels 1, 2, 3 and 4, and $\mathrm{S}=$ number of nucleoids analyzed, including level 0 (Jaloszynski et al., 1999; Collins, 2004).

\section{Histology of the gonads}

After feed exposure, gonads of both sexes were collected, fixed with Davidson solution for $24 \mathrm{~h}$, transferred to $70 \%$ ethanol, embedded in paraffin using an automatic tissue processor $\left(\mathrm{OMA}^{\circledR}\right.$ DM-40, São Paulo, Brazil), cut into 5- $\mu$ m slices in a Leica RM2235 manual microtome (Leica Microsystems, Nussloch, Germany) and stained with hematoxylin-eosin for histological analyses (light microscopy). Oocytes were classified into five stages according to maturation 
scale (Wallace and Selman, 1981). Morphometric analyses were performed with the software Image-pro Plus 5.1, where 30 oocytes at stage V (mature oocytes) of each treatment were analyzed for comparative analysis of the diameter of the oocytes (Homklin et al., 2011). For males, quantification of sperm was carried out by calculating the average areas of the spermatic cysts.

\section{Statistical analysis}

Statistical analysis was carried out using SPSS (Statistical Package for the Social Sciences) version 17.0. Data were expressed as the mean \pm SEM (standard error of mean) and $\mathrm{P}<0.05$ was considered statistically significant. The continuous variables were tested for normal distribution with the Shapiro-Wilk test. Possible differences between the groups were investigated by the independent-samples $t$-test or Mann Whitney U test (when the data were not normally distributed).

\section{RESULTS}

\section{MN frequency, NA, and DNA damage}

The only significant difference between the control and MT groups was for NA of $A$. bimaculatus $(\mathrm{P}=0.002)$. There were no significant differences for MN frequencies and DNA damage in either species (Table 1).

\begin{tabular}{|c|c|c|c|c|c|}
\hline \multirow[t]{2}{*}{ Group } & \multirow[t]{2}{*}{ Animals (N) } & \multicolumn{2}{|c|}{ Micronucleus test } & \multicolumn{2}{|c|}{ Comet assay } \\
\hline & & MN & NA & $\%$ Moderate damage & $\%$ High damage \\
\hline \multicolumn{6}{|c|}{ O. niloticus } \\
\hline Control & 10 & $0.10 \pm 0.10$ & $9.80 \pm 4.00$ & $22.46 \pm 2,40$ & $33.06 \pm 6.43$ \\
\hline \multirow{2}{*}{ MT } & 10 & $0.00 \pm 0.00$ & $12.80 \pm 4.07$ & $25.45 \pm 1.55$ & $21.73 \pm 4.77$ \\
\hline & $P$ values & 0.317 & 0.288 & 0.330 & 0.187 \\
\hline \multicolumn{6}{|c|}{ A.bimaculatus } \\
\hline Control & 10 & $0.00 \pm 0.00$ & $2.80 \pm 0.66$ & $20.97 \pm 3.11$ & $39.17 \pm 8.01$ \\
\hline \multirow[t]{2}{*}{ MT } & 10 & $0.40 \pm 0.22$ & $9.00 \pm 1.70$ & $19.08 \pm 2.86$ & $38.50 \pm 8.97$ \\
\hline & $P$ values & 0.068 & 0.002 & 0.401 & 0.895 \\
\hline
\end{tabular}

$\mathrm{N}=$ sample size; $\mathrm{MT}=$ food containing 17 - $\alpha$-methyltestosterone; $\mathrm{MN}=$ micronucleus frequency; $\mathrm{NA}=$ nuclear abnormalities. The data correspond to the means and to the standard error of mean (SEM) of the frequencies of MN, NA and percentage of comets of classes 1 and 2 (moderate damage) and of comets of classes 3 and 4 (elevated damage) with respect to the total damage. For $O$. niloticus, $\mathrm{P}$ values of $\mathrm{MN}$ and NA were generated by the independent-sample $t$-test, while the other $\mathrm{P}$ values were generated by the Mann-Whitney U-test. For $A$. bimaculatus, $\mathrm{P}$ values were generated by the Mann-Whitney U-test.

\section{Histology and morphometric analysis of mature oocytes and sperm}

The gonadal histology was similar to that of other teleosts. Ovaries were found in the dorsal region of the coelomic cavity and showed good visibility of oocytes since they were adult individuals. O. niloticus shows typical oogenesis for partial spawning, unlike $A$. bimaculatus, which displays total spawning. The profusion of tissue in the degeneration process, sometimes easily detected as atresic follicles, differs histologically as regards the control gonads, especially in $O$. niloticus. Oocytes V from $O$. niloticus were significantly smaller in diameter when exposed to MT 
compared to control $(\mathrm{P}=0.000)$ (Table 2, Figure 1a,b). Adverse effects on sperm production were observed for males of $O$. niloticus (Figure 1c,d). For A. bimaculatus, no significant difference was observed for oocyte $\mathrm{V}$ diameter (Figure 1e,f). Sperm production decreased significantly in the MT group with respect to the control for A. bimaculatus $(\mathrm{P}=0.006)$ (Table 2, Figure $1 \mathrm{~g}, \mathrm{~h})$.

\begin{tabular}{|c|c|c|c|}
\hline Group & Animals $(\mathrm{N})$ & Diameter $(\mu \mathrm{m})$ & Area $(\mu \mathrm{m})$ \\
\hline \multicolumn{4}{|c|}{ O. niloticus } \\
\hline Control & 10 & $722.47 \pm 47.2$ & $2410.13 \pm 122.84$ \\
\hline MT & $\begin{array}{c}10 \\
\text { P values }\end{array}$ & $\begin{array}{l}383 \pm 14.65 \\
0.000\end{array}$ & $\begin{array}{c}3125.31 \pm 349.29 \\
0.667\end{array}$ \\
\hline \multicolumn{4}{|c|}{ A. bimaculatus } \\
\hline Control & 10 & $497.11 \pm 17.26$ & $8653.94 \pm 387.92$ \\
\hline \multirow[t]{2}{*}{ MT } & 10 & $476.21 \pm 13.87$ & $6932.12 \pm 387.69$ \\
\hline & $P$ values & 0.239 & 0.006 \\
\hline
\end{tabular}

$\mathrm{N}=$ sample size; $\mathrm{MT}=$ food containing 17- $\alpha$-methyltestosterone. $\mathrm{P}$ values were generated by the Mann-Whitney U-test.

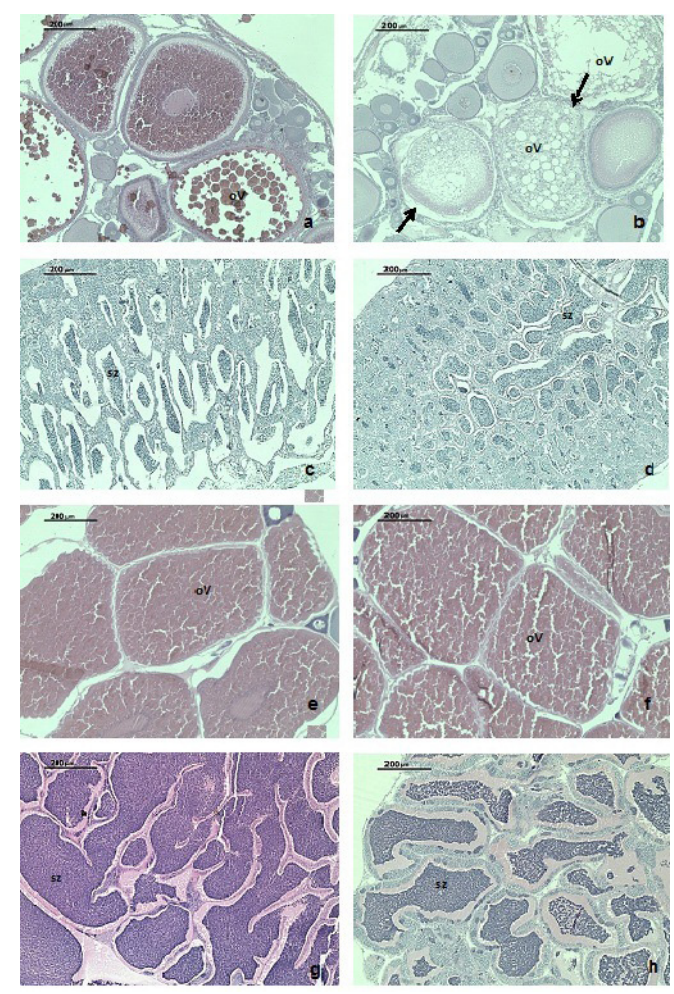

Figure 1. Histology of the gonads of Oreochromis niloticus (a to d) and Astyanax bimaculatus (e to h). a. and e. Control females; b. and f. females treated with food containing MT; c. and g. control males; $\mathbf{d}$. and h. males treated with food containing MT. (a) Normal development of ovarian tissue in female O. niloticus in the control group. (b) Degeneration of ovarian tissue of adult $O$. niloticus exposed to $60 \mathrm{mg} / \mathrm{L}$ methyltestosterone for 28 days. The arrows indicate ovarian degeneration. (g) Normal production of cysts of spermatozoids in male A. bimaculatus in the control group. (h) Decrease in spermatogenesis in A. bimaculatus males exposed to $60 \mathrm{mg} / \mathrm{L}$ methyltestosterone for 28 days. Hematoxylin and eosin stain; scale bar $=200 \mu \mathrm{m}$. (oV) mature oocytes; (sz) spermatozoids. 
Testes were located dorsally and sperm were visible macroscopically, indicating sexual maturity. All the histologically assessed testicles showed male germinative epithelium within the seminiferous tubules. This germinative epithelium was formed by primary and secondary spermatogonia, spermatocytes I and II and spermatids. The development of these cells takes place through cysts except for the primary spermatogonia and spermatozoids. The spermatozoids fill the lumen and drain in the direction of the central region, which is formed by dense connective tissue, with abundant vascularization and sperm drainage ducts covered by epithelium. In males, a moderate effect on sperm production were observed for $O$. niloticus (Figures $1 \mathrm{c}$ and $\mathrm{d}$ ), but a highly significant decrease in the sperm production occurred in the exposed group of $A$. bimaculatus $(\mathrm{P}=0.006)$ (Table 2, Figure $1 \mathrm{~g}$ and $\mathrm{h}$ ) compared to control group. Complete masculinization and ovotest development did not occur for both species.

\section{DISCUSSION}

\section{Genotoxicity biomarkers and biological system}

During MN analyses, some authors have observed the occurrence of NA other than $\mathrm{MN}$, suggesting that they must be taken into consideration along with conventional MN analysis. The formation of morphological alterations in the nuclear envelope, such as blebbed nuclei (those that display a relatively small evagination from the envelope, which seems to contain euchromatin), lobed nuclei (showing evaginations larger than those from blebbed nuclei) and notched nuclei (showing a remarkable notch containing nuclear material) have been reported in fish erythrocytes, as a consequence of exposure to environmental and chemical contaminants of genotoxic, mutagenic or carcinogenic potential, although the mechanisms responsible for such abnormalities have not yet been described (da Silva and Fontanetti, 2006). However, these abnormalities have been used by several authors as indicators of genotoxic damage and cytogenetic toxicity (Ayllon and Garcia-Vazquez, 2000; Cavaş and Ergene-Gözükara, 2003). In our study, $17 \alpha$-methyltestosterone showed no genotoxic or clastogenic effect evaluated respectively by the comet assay or MN test in the two species studied. However, the non-target species, A. bimaculatus, showed sensitivity to MT as regards NA, indicating that MT induced cytogenetic toxicity in this species.

There has been a study of rainbow trout (Oncorhynchus mykiss) treated with a single dose of food containing $30 \mathrm{mg}$ methyltestosterone per $\mathrm{kg}$ fish; the oral bioavailability of methyltestosterone from food was about $70 \%$. This percentage was calculated using the plasma concentration-time profiles, and the results suggested that MT administered orally from food was more slowly metabolized than testosterone (Vick and Hayton, 2001). In our study, the results with $A$. bimaculatus suggest that this species is more sensitive than $O$. niloticus, and the slower metabolism of MT can be the main cause of the cytotoxicity found, although the effect of secondary metabolites cannot be discarded.

\section{Histology of gonads}

Androgens are a class of steroids that are responsible for the primary and secondary sex characteristics of the male. These steroids possess potent anabolic or growth-promoting properties (Hana et al., 2008). Estrogenic/androgenic controls on reproduction/development in 
fish may differ substantially from those in higher vertebrates to the point that mammalian (rat) screening methods may not identify potential endocrine-disrupting chemicals (EDCs) in this important class of animals (Ankley et al., 2001). Little research has addressed how androgenic chemicals, such as MT, adversely affect the reproduction of fish (Ankley et al., 2001; Kang et al., 2008), but as opposed to human health effects, significant evidence currently exists for adverse EDC effects in a variety of wildlife species, including fish (Ankley et al., 2001). MT has been reported as causing gonadal alterations in some fish species, producing morphological sex reversal in juvenile females of fathead minnows (Pimephales promelas) (Zerulla et al., 2002), degenerate oocytes (that is, oil droplet; indicative of regression of oogenesis), masculinization of the secondary sex characteristics in females and reduction in fecundity of adult medaka (Oryzias latipes), besides hatchability and survival rate of the offspring of this species (Kang et al., 2008). Our study corroborates these previous reports, since the treatment with MT caused growth inhibition and degeneration of mature oocytes in O. niloticus (demonstrated by a decrease in the diameter of the oocytes), while in A. bimaculatus, it caused a reduction in spermatozoa production. The action of MT in O. niloticus is in accordance with its use in fish farming to produce monosex males. Our results suggest that the discharge of fish farm water onto the surface of aquatic ecosystems can be harmful to native species, since in $\mathrm{A}$. $b i$ maculatus, a native Brazilian species, MT was cytotoxic and compromised spermatogenesis.

\section{CONCLUSIONS}

In this study, MT showed cytogenetic toxicity only in A. bimaculatus, besides causing growth inhibition and degeneration of mature oocytes of $O$. niloticus and reduction in spermatozoa production in A. bimaculatus. Although the reproductive effects on $O$. niloticus are in accordance with its use in fish hatcheries to produce monosex males, the results obtained with A. bimaculatus highlight the importance of this study for the environment, indicating that the discharge of fish hatchery water onto the surface of aquatic ecosystems should be avoided due to risks to reproduction of native species.

\section{ACKNOWLEDGMENTS}

Research supported by the Brazilian National Council for Technological and Scientific Development $(\mathrm{CNPq})$ and the Coordination for Further Training of Graduate Staff (CAPES). We thank the Pisciculture Center of the Federal District Government for the supply of fish for the study.

\section{REFERENCES}

Al-Sabti K and Metcalfe CD (1995). Fish micronuclei for assessing genotoxicity in water. Mutat. Res. 343: 121-135. Ankley GT, Jensen KM, Kahl MD, Korte JJ, et al. (2001). Description and evaluation of a short-term reproduction test with the fathead minnow (Pimephales promelas). Environ. Toxicol. Chem. 20: 1276-1290.

Arslan T and Phelps RP (2004). Production of monosex male black crappie, Pomoxis nigromaculatus, populations by multiple androgen immersion. Aquaculture 234: 561-573.

Ayllon F and Garcia-Vazquez E (2000). Induction of micronuclei and other nuclear abnormalities in European minnow Phoxinus phoxinus and mollie Poecilia latipinna: an assessment of the fish micronucleus test. Mutat. Res. 467: 177-186.

Bolognesi C, Perrone E, Roggieri P, Pampanin DM, et al. (2006). Assessment of micronuclei induction in peripheral erythrocytes of fish exposed to xenobiotics under controlled conditions. Aquat. Toxicol. 78 (Suppl 1): S93-S98. 
Buschini A, Martino A, Gustavino B, Monfrinotti M, et al. (2004). Comet assay and micronucleus test in circulating erythrocytes of Cyprinus carpio specimens exposed in situ to lake waters treated with disinfectants for potabilization. Mutat. Res. 557: 119-129.

Cavaş T and Ergene-Gözükara S (2003). Micronuclei, nuclear lesions and interphase silver-stained nucleolar organizer regions (AgNORs) as cyto-genotoxicity indicators in Oreochromis niloticus exposed to textile mill effluent. Mutat. Res. 538: 81-91.

Collins AR (2004). The comet assay for DNA damage and repair: principles, applications, and limitations. Mol. Biotechnol. 26: $249-261$.

Collins AR (2009). Investigating oxidative DNA damage and its repair using the comet assay. Mutat. Res. 681: 24-32.

da Silva ST and Fontanetti CS (2006). Micronucleus test and observation of nuclear alterations in erythrocytes of Nile tilapia exposed to waters affected by refinery effluent. Mutat. Res. 605: 87-93.

Dusinska M and Collins AR (2008). The comet assay in human biomonitoring: gene-environment interactions. Mutagenesis 23: 191-205.

Grisolia CK and Starling FL (2001). Micronuclei monitoring of fishes from Lake Paranoa, under influence of sewage treatment plant discharges. Mutat. Res. 491: 39-44.

Grisolia CK, Rivero CLG, Starling FLRM, Silva ICR, et al. (2009). Profile of micronucleus frequencies and DNA damage in different species of fish in a eutrophic tropical lake. Genet. Mol. Biol. 32: 138-143.

Hana HY, Khalil WK, Elmakawy AI and Elmegeed GA (2008). Androgenic profile and genotoxicity evaluation of testosterone propionate and novel synthesized heterocyclic steroids. J. Steroid Biochem. Mol. Biol. 110: 284-294.

Homklin S, Ong SK and Limpiyakorn T (2011). Biotransformation of 17alpha-methyltestosterone in sediment under different electron acceptor conditions. Chemosphere 82: 1401-1407.

Hooftman RN and de Raat WK (1982). Induction of nuclear anomalies (micronuclei) in the peripheral blood erythrocytes of the eastern mudminnow Umbra pygmaea by ethyl methanesulphonate. Mutat. Res. 104: 147-152.

Hornung MW, Jensen KM, Korte JJ, Kahl MD, et al. (2004). Mechanistic basis for estrogenic effects in fathead minnow (Pimephales promelas) following exposure to the androgen 17alpha-methyltestosterone: conversion of 17alphamethyltestosterone to 17alpha-methylestradiol. Aquat. Toxicol. 66: 15-23.

Jaloszynski P, Kujawski M, Wasowicz M, Szulc R, et al. (1999). Genotoxicity of inhalation anesthetics halothane and isoflurane in human lymphocytes studied in vitro using the comet assay. Mutat. Res. 439: 199-206.

Kang IJ, Yokota H, Oshima Y, Tsuruda Y, et al. (2008). The effects of methyltestosterone on the sexual development and reproduction of adult medaka (Oryzias latipes). Aquat. Toxicol. 87: 37-46.

Kim IY and Hyun CK (2006). Comparative evaluation of the alkaline comet assay with the micronucleus test for genotoxicity monitoring using aquatic organisms. Ecotoxicol. Environ. Saf. 64: 288-297.

McKenna DJ, McKeown SR and McKelvey-Martin VJ (2008). Potential use of the comet assay in the clinical management of cancer. Mutagenesis 23: 183-190.

Pacheco M and Santos MA (2002). Biotransformation, genotoxic, and histopathological effects of environmental contaminants in European eel (Anguilla anguilla L.). Ecotoxicol. Environ. Saf. 53: 331-347.

Pandian TJ and Sheela SG (1995). Hormonal induction of sex reversal in fish. Aquaculture 138: 1-22.

Papoulias DM, Noltie DB and Tillitt DE (2000). Effects of methyl testosterone exposure on sexual differentiation in medaka, Oryzias latipes. Mar. Environ. Res. 50: 181-184.

Pawlowski S, Sauer A, Shears JA, Tyler CR, et al. (2004). Androgenic and estrogenic effects of the synthetic androgen 17alpha-methyltestosterone on sexual development and reproductive performance in the fathead minnow (Pimephales promelas) determined using the gonadal recrudescence assay. Aquat. Toxicol. 68: 277-291.

Rivero CL, Barbosa AC, Ferreira MF, Dorea JG, et al. (2008). Evaluation of genotoxicity and effects on reproduction of nonylphenol in Oreochromis niloticus (Pisces: Cichlidae). Ecotoxicology 17: 732-737.

Singh NP, McCoy MT, Tice RR and Schneider EL (1988). A simple technique for quantitation of low levels of DNA damage in individual cells. Exp. Cell Res. 175: 184-191.

Smith RJ (1974). Effects of 17 alpha-methyltestosterone on the dorsal pad and tubercles of fathead minnows (Pimephales promelas). Can. J. Zool. 52: 1031-1038.

Udroiu I (2006). The micronucleus test in piscine erythrocytes. Aquat. Toxicol. 79: 201-204.

Vick AM and Hayton WL (2001). Methyltestosterone pharmacokinetics and oral bioavailability in rainbow trout (Oncorhynchus mykiss). Aquat. Toxicol. 52: 177-188.

Wallace RA and Selman K (1981). Cellular and dynamic aspects of oocyte growth in teleosts. Am. Zool. 21: 325-343.

Zerulla M, Länge R, Steger-Hartmann T, Panter G, et al. (2002). Morphological sex reversal upon short-term exposure to endocrine modulators in juvenile fathead minnow (Pimephales promelas). Toxicol. Lett 131: 51-63. 